\title{
The Diffusion of the Legitimate and the Diffusion of Legitimacy
}

\author{
Gabriel Rossman \\ University of California, Los Angeles
}

\begin{abstract}
This article models the implications of innovations being nested within categories. In effect, social actors assess the legitimacy of innovations vis-à-vis conformity to categories such that a sufficiently legitimate innovation may be adopted without direct reference to the behavior of peers. However, when innovations lack categorical legitimacy, actors default to proximately peer-oriented heuristics such as information cascades. Eventually, if enough similarly novel innovations achieve widespread popularity, their conventions will become accepted as a legitimate category. Thus density creates legitimacy, but this density can be at the level of the particular innovation or of the category within which it is embedded.
\end{abstract}

Keywords: diffusion; institutions; categories; compatibility

Editor(s): Jesper Sørensen, Ezra Zuckerman; Received: September 17, 2013; Accepted: September 30, 2013; Published: March 3, 2014

Citation: Rossman, Gabriel. 2014. "The Diffusion of the Legitimate and the Diffusion of Legitimacy." Sociological Science 1: 49-69. D0I: 10.15195/v1.a5

Copyright: (C) 2014 Rossman. This open-access article has been published and distributed under a Creative Commons Attribution License, which allows unrestricted use, distribution and reproduction, in any form, as long as the original author and source have been credited.

$\mathrm{T}^{\mathrm{N}}$ understanding when and how people act, sociologists have tended to be especially interested in "situations where many actors behave in ways contingent on one another" (Granovetter 1978:1442). Indeed, there is often a strong presumption that only such dynamic interdependence is truly social, as in the famous passage from Weber's (1978) essay on social action in which he suggests that "if at the beginning of a shower a number of people on the street put up their umbrellas at the same time, this would not ordinarily be a case of action mutually oriented to that of each other, but rather of all reacting in the same way to the like need of protection from the rain" (p. 23). However, Weber's position is open to the critique that "it never occurred to him that umbrellas are only found in certain societies, and neither manufactured nor used in all" (Elias 1978:120); that is, sociologists from Weber through the present interested in how action might be social have mostly been thinking of whether action is proximately contingent on others - a tendency that has only increased with the recent interest in models based on networks, cascades, and other varieties of complexity. However, what much of this research overlooks is that even behavior that is proximately indifferent to peer behavior may be ultimately social in that the actor's repertoire or tool kit is socially derived (Swidler 1986; Tilly 1983). We can thus usefully distinguish between different levels of abstraction in the nature of social action.

Paradoxically, there may well be a trade-off between proximately social and ultimately social action. A behavior that is completely congruent with social expectations may be performed immediately on opportunity to do so, without reference to peers. In contrast, a dubious act will be performed more hesitantly, furtively looking to see whether others are acting likewise. For instance, applause is a thoroughly legitimate act, and most audience members understand what aspects of a speech merit applause, so audience members tend to erupt into applause simultaneously as each member reacts directly to the applause lines, without waiting to see if peers are behaving similarly (Heritage and Greatbatch 1986) 1 In contrast, booing is a boorish act, and so audiences tend to creep gradually into booing, with each member waiting to see how many others have broached rudeness (Clayman 1993). Like-

\footnotetext{
${ }^{1}$ Note that this finding assumes an understanding that applause is restricted to immediately after a rhetorical unit or musical movement and that when such a unit has been completed is obvious. This is not especially complicated for oratory but is somewhat complicated for music. In some times (e.g., classical music prior to about 1900) and for some genres (e.g., jazz), this distinction does not hold, and under these conditions, applause is less focused and may well be more sensitive to peer influence (Ross 2010).
} 
wise, the paradigmatic case of density-dependent behavior is the downright criminal behavior of rioting (Granovetter 1978).

Ironically, it is the shared norms of rhetoric and applause that mean we decide to applaud autonomously and the taboos against booing and rioting that make them contagious. Thus legitimacy can provide a Schelling point for coordination without communication (Schelling 1960). However, when innovations lack sufficient legitimacy, actors default to proximately peer-oriented heuristics such as information cascades and cohesive contagion. Two levels of social interaction determine an agent's behavior: the general expectations of how an audience generally behaves and the actual behavior of the other people in the room. The aim of this article is to synthesize diffusion and understanding of categorical legitimacy and institutions so as to understand how behaviors such as bursting into applause or opening an umbrella can be proximately atomistic but ultimately social.

The remainder of this article reviews the literature on diffusion and categories to derive three hypotheses about categorical legitimacy. An agent-based computer simulation illustrates how qualitative shifts in the nature of diffusion from s-curves to Zeno's paradox are emergent from legitimacy, operationally understood as categorical density. The conclusion argues that one of the reasons that much of the diffusion literature finds s-curves is that they often study innovations that lack local legitimacy and thus they are conflating the diffusion of the particular innovation and the category and institutions within which it is embedded. Finally, the conclusion suggests reconceptualizing nearly simultaneous action from "exogenous" diffusion to coordination without communication based on shared expectations.

\section{The Diffusion of Innovation}

The diffusion of innovation is a set of approaches seeking to understand when different actors in a social system will adopt an innovation (Rogers and Seidel 2002; Strang and Soule 1998; Wejnert 2002). Broadly speaking, there are two models for how innovations diffuse through social systems: endogenous and exogenous. In this section,
I first describe each of these models and then describe a more generalized framework that allows comparing them. Although I adopt the common nomenclature, later sections of the article will undermine the assumptions underlying these terms that so-called endogenous diffusion is social whereas so-called exogenous diffusion is atomistic.

\section{Endogenous Diffusion}

In the endogenous diffusion model, how fast an innovation spreads is a function of how popular it is already. As such, the proportion of the system that has adopted the innovation over time starts out low; slowly builds to a critical mass, where it achieves exponential growth; and finally levels off as it saturates the system ${ }^{2}$ The model is sometimes called an "s-curve" because if you plot how many people have done something over time, the graph resembles an italicized letter $s$. The curve describes both the trivial and the essential, the ephemeral and the enduring, providing a good description of everything from how YouTube videos go viral over the space of a few weeks to how hybrid seed corn became ubiquitous on Iowa farms over the course of two decades to the spread of Christianity throughout the Roman Empire or the conversion of local populations to Islam under the Caliphate (Crane and Sornette 2008; Ryan and Gross 1943; Stark 1996; Turchin 2003).

Endogenous growth is a general pattern that can encompass a variety of mechanisms as to why an innovation would spread faster if it had a larger user base $3^{3}$ The most commonly assumed

\footnotetext{
${ }^{2}$ In other words, the hazard for adoption is a function of lagged adoptions (Bass 1969; Mahajan and Peterson 1985).

${ }^{3} \mathrm{~A}$ special case of endogenous diffusion can occur when the proximate cause of an actor adopting is in some sense outside of the actor's community, but this proximate cause is itself tightly coupled to community behavior. That is, diffusion may still be endogenous even if the endogenous effect is mediated by a judgment device. For instance, suppose that book readers are attentive to the New York Times best-seller list or a website download count (or to retail inventory practices based on such a list) but are not directly attentive to their peers (Karpik 2010; Sorensen 2007; Salganik, Dodds, and Watts 2006). In an ontological sense, the Times is outside of the community of book consumers, and so there is a certain surface appeal to considering this diffusion "exogenous." However, this would be a mistake as a popularity judgment device like a best-seller list reacts mechanically to the aggregate
} 
mechanism is contagion, whereby those who have adopted the innovation directly promote the innovation to those with whom they are in contact (Dawkins 1976; Rogers 2003; Ryan and Gross 1943). A variant is structural equivalence contagion, wherein people imitate their rivals rather than their contacts (Burt 1987). Threshold models do not necessarily rely on social networks but simply aggregate popularity (Granovetter 1978). Among the most popular threshold models is the information cascade, where potential adopters use the number of prior adoptions as a heuristic of quality - a logic encapsulated in the album title 50,000,000 Elvis Fans Can't Be Wrong (Banerjee 1992; Bikhchandani, Hirschleifer, and Welch 1992; Salganik et al. 2006; Salganik and Watts 2008) . ${ }^{4}$ In all of these mechanisms, the potential adopter is using prior adoption (by contacts, rivals, or the field as a whole) as a source of credible information about the innovation's desirability. Another class of threshold models is the "network externality" model, which argues that the number of prior adoptions is not just a source of information but raises the objective utility of adoption by facilitating direct or indirect coordination among those who have adopted the same innovation. For instance, harmonizing on even a suboptimal technical standard allows the development of an open market for skilled labor familiar with the standard or parts compatible with the standard, thereby making conforming to the technical standard attractive to both firms and labor (David 1985). Likewise, as a communication technology grows popular, both in general and with one's network alters, adopting it becomes more attractive (DiMaggio and Garip 2011).

\section{Exogenous Diffusion}

Though endogenous dynamics get most of the attention in the diffusion literature, many innovations see little or no proximate role for peer influence. In such circumstances, potential adopters respond directly to exogenous forces. Because by

behavior of consumers, and so in an analytical sense, we would describe this model of book consumption as endogenous.

${ }^{4}$ Snob and fashion cycle models (e.g., Berger and LeMens 2009; Leibenstein 1950) are related to information cascades but do not assume monotonic effects of present popularity on the hazard for future adoptions. definition these exogenous forces do not increase as a result of the user base, the proportion of new adopters remains the same in every period (i.e., there is a constant hazard) 5 This results in a concave curve with immediate fast growth followed by slow growth, much like Zeno's paradox of Achilles and the Tortoise. This pattern describes when doctors first prescribed tetracycline, when radio stations will begin playing a new pop song, when corporations designated an $\mathrm{EEO} / \mathrm{AA}$ compliance officer, and when people learned about President Eisenhower's stroke or the September 11 terrorist attacks (Dobbin and Sutton 1998; Rogers and Seidel 2002; Rossman, Chiu, and Mol 2008; Valente 1993). Perhaps most notably, civil service reform spread exogenously among municipalities when it was mandated by state governments but endogenously when the state government took no action (Tolbert and Zucker 1983) ${ }^{6}$ Figure 1 contrasts the endogenous and exogenous diffusion patterns.

Exogenous diffusion from such sources as mass media and change agents usually drives awareness of the innovation, but it often takes endogenous peer influence to drive adoption of the innovation (Van den Bulte and Lilien 2010; Rogers 2003). Many innovation studies find that potential adopters first learn about the innovation from the mass media or from a "change agent" (e.g., a salesman, missionary, or public health worker), but potential adopters view such sources of information as not credible because they are biased in favor of the innovation and/or are outsiders who do not understand how the innovation would apply in the local context. 7 For instance, Iowa farmers became aware of hybrid corn following an

\footnotetext{
${ }^{5}$ The usual model is to treat exogenous forces as constant, but the model can be extended to accommodate time-varying data on the intensity of exogenous forces (Van den Bulte and Lilien 2001).

${ }^{6}$ The present article is similar to Tolbert and Zucker (1983) in many respects but different in others. The earlier work focuses on the actor's context (i.e., whether a city was in a reform state), whereas this article focuses on the innovation's relationship to prior innovations. Furthermore, whereas that work shows the effect of macro on micro, this article also shows how the macro is emergent from the micro.

${ }^{7}$ Note that change agents (i.e., outsiders to a social system who attempt to promote diffusion) are not to be confused with "opinion leaders" (i.e., particularly central members of a social system whose adoption of an innovation may help its diffusion) (Katz and Lazarsfeld 1955; Rogers 2003). For purposes of this article, opinion leaders
} 


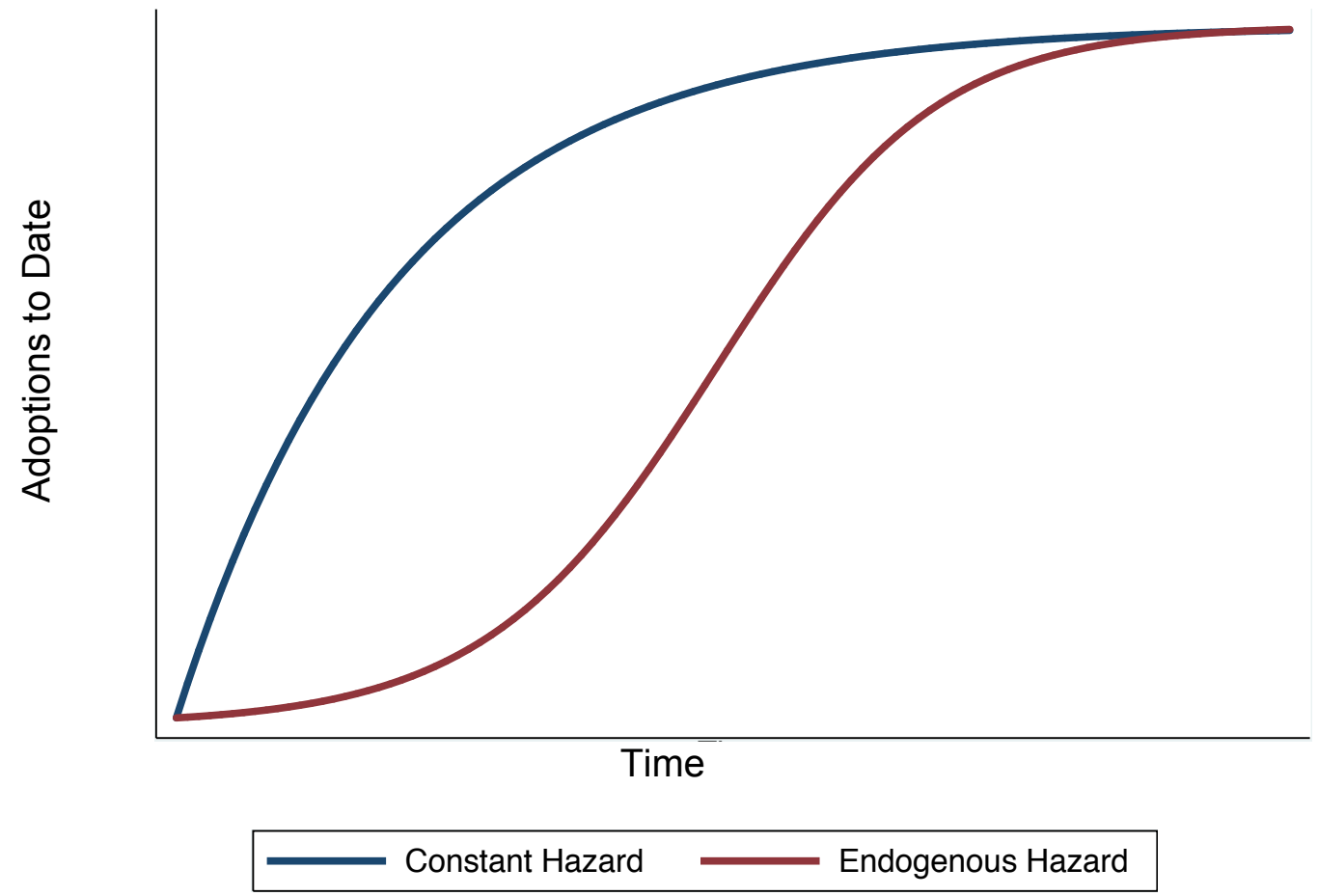

Figure 1: Ideal-typical innovation diffusion curves.

exogenous pattern from such sources as salesmen and farm journals but adopted hybrid corn following an endogenous pattern on the basis of seeing their neighbors' success with the corn. Later sections of this article will emphasize adoption but assume as a scope condition that awareness has already been achieved.

\section{The Bass Model as General Form for Endogenous and Exogenous Diffusion}

Bass (1969) provides a generalized model of diffusion encompassing both endogenous and exogenous diffusion. The Bass model is often described as $f_{t}=\left(p+q F_{t}\right)\left(1-F_{t}\right)$, where $F_{t}$ is the proportion of potential adopters having already adopted; $f_{t}=\Delta F_{t} ; p$ is the exogenous rate; and $q F_{t}$ is the endogenous rate at $t: 8$ Because the endoge-

are an aspect of endogenous diffusion, whereas change agents are an aspect of exogenous diffusion.

${ }^{8} \mathrm{~A}$ common alternate nomenclature for the same model uses $a, b$, and $N$ instead of $p, q$, and $F$ (Mahajan and nous model is a special case of this model when $p$ is zero and the exogenous model is a special case when $q$ is zero, one can thus test for the relative importance of exogenous and endogenous dynamics across cases by fitting the model and looking for the relative size of the exogenous $(p)$ and endogenous $(q)$ coefficients. Thus the shape of a cumulative adoption curve can have a theoretical interpretation where a concave curve (high $p$ ) implies exogenous forces like advertising, whereas an s-curve (high $q$ ) implies endogenous dynamics like word of mouth (Bass 1969; Van den Bulte and Joshi 2007; Mahajan and Peterson 1985; Rossman et al. 2008; Valente 1993) ${ }^{9}$

Peterson 1985; Rossman et al. 2008; Valente 1993). Also note that alternative specifications like the Gompertz logarithmic risk pool function allow for issues like heterogeneous thresholds (Cleves, Gould, and Gutierrez 2004; Mahajan and Peterson 1985).

${ }^{9}$ Like much of the literature, the canonical Rogers (2003) text allows for exogenous sources of diffusion but gives much more emphasis to endogenous processes. Specifically, he describes "innovators" (roughly the first 3 percent of adoptions) as being inspired by exogenous sources. However, his illustrations show the cumulative 
The Bass curve's general form allows for diffusion processes that do not perfectly match the ideal type of pure endogenous or exogenous diffusion but form a hybrid of the two. When $q$ is about 2 to 10 times the size of $p$, early adoptions are mostly driven by exogenous sources, but over time these forces are eclipsed by the exponential dynamics of endogenous diffusion. The "mixed influence" model originally dates back to a study of refrigerators, televisions, and other consumer appliances after the war (Bass 1969). It has recently been revived as the "big seed" model that innovation is most effective when it starts broadly (Watts and Dodds 2007), in contrast to the argument that network hubs are key to diffusion (Gladwell 2000; Iyengar, Van den Bulte, and Valente 2011; Travers and Milgram 1969).

\section{Summary of Diffusion}

The literature distinguishes between endogenous and exogenous models of diffusion and associates the latter with such things as the volume of advertising aimed at consumers. This article does not dispute these interpretations but develops the argument that a necessary condition for exogenous diffusion is the perceived legitimacy of the proffered innovation. If an innovation does not resonate as legitimate, it will be prohibitively difficult for even strenuous external salesmanship to find many takers. Rather, potential adopters may become aware of a dubious new product or practice from these exogenous efforts, but actual adoption will be inspired by peers (Van den Bulte and Lilien 2010; Rogers 2003; Ryan and Gross 1943). Ironically, then, an innovation can only diffuse "exogenously" to the extent that it is consonant with the local system. Innovations that are perceived as disruptive or imposed by outside actors will only be adopted by endogenous processes or not at all.

\section{Categories and Legitimacy}

Just as firms are nested within industries or fields, so are innovations nested within categories (Hsu and Hannan 2005). For instance, particular artworks are nested within genres and particular

adoption function as an s-curve and the first derivative as a normal distribution, which is only consistent with an essentially endogenous diffusion process. publicly traded firms within industries (DiMaggio 1987; Henisz, Zelner, and Guillen 2005; Zuckerman 1999). For purposes of exposition, I assume that each innovation is cleanly nested within a single category, but I will revisit this issue in the assumptions section of the article.

When an actor decides whether to adopt an innovation, the implicit or explicit process is to first determine whether the innovation is a legitimate member of a category (commensuration) and then to compare the innovation to other members of that category (evaluation) (Espeland and Stevens 1998; Hsu and Hannan 2005; Phillips and Zuckerman 2001). Thus innovations must conform to the conventions of a salient, appropriate, and nontrivial category even to be considered for immediate adoption.

This section provides an extended argument for the mutual dependency of micro (innovations) and macro (categories). I first argue that established categories are a necessary (but not sufficient) condition for exogenous diffusion of innovation. I follow by suggesting that innovations within weak categories will necessarily diffuse endogenously. I then close the section by showing how micro in turn affects macro such that each successfully diffused innovation contributes to the density of its category and thereby affects the diffusion of subsequent innovations in the category.

\section{Only Innovations from Established Categories May Spread Exogenously}

Diffusion can be rapid when the innovation is similar to incumbent practices and compares favorably along well-established criteria (Randles 1983). The drug tetracycline was rapidly adopted by doctors, in large part because it was a member of a product category (antibiotics) that had been in widespread use since the war (Coleman, Katz, and Menzel 1966). This meant that doctors understood what antibiotics were, why they were desirable, and how to evaluate the quality of a particular antibiotic against competitors. In short, though tetracycline was an innovation, it was well situated within a legitimate category. Physicians were able to understand almost immediately that tetracycline was both a member of a legitimate category and high quality by the standards of that category. As such they adopted it rapidly, with only a little regard to the behav- 
ior of rivals, and it is telling that doctors who had significant experience with similar drugs were especially likely to start prescribing tetracycline immediately 10

Of course, not all innovations that conform to incumbent categories diffuse by the exogenous pattern. There are a host of reasons why an actor who is completely comfortable with an innovation's category might nonetheless delay adoption:

- Strong network externalities: A product might be more useful if it is popular (David 1985; DiMaggio and Garip 2011). This is especially problematic if there is uncertainty about the innovation's eventual popularity, as can be the case when there is a format war between two similar innovations.

- Limited availability: Actors who might be interested in adopting the innovation could find it unavailable to them. This can involve difficulties in scaling up manufacturing or legal monopolies (e.g., intellectual property rights).

- High initial price: The price charged to early adopters might be very high, either to amortize development costs or because manufacturing has economies of scale that have yet to scale up. As the price goes down, more users will be attracted.

- Limited marginal improvement: An innovation may offer only incremental advantages over an incumbent innovation, and so many actors will postpone adoption to follow the incumbent innovation's replacement cycle (Pae and Lehmann 2003).

\footnotetext{
${ }^{10}$ The original report of tetracycline diffusion emphasized network contagion diffusion, and it is still often cited as a case of either cohesion contagion or structural equivalence contagion (Coleman et al. 1966; Burt 1987). However, secondary analyses have established that although there may have been some contagion, it was a fairly small component, as doctors adopted the drug too rapidly to have been much influenced by peers (Marsden and Podolny 1990; Valente 1993; Van den Bulte and Lilien 2001). Some secondary analyses of the data still find some endogenous dynamics (Friedkin 2010; Strang and Tuma 1993). Whether one measures contagion effects in the tetracycline data is largely determined by such specification issues as city-level random intercepts and whether one assumes peer influence must be lagged or can be simultaneous.
}

- Complementarity with other innovations: An innovation may only be useful in conjunction with other innovations. This is not problematic if the innovation is backward compatible with the complements of older innovations in the same category. For instance, mobile phones have always been able to make calls to landlines. However, if an innovation is complementary with another innovation which is not itself widely extant, this will hamper diffusion.

The 2006 release of the Blu-ray video disc format illustrates several of these problems. Blu-ray was a member of a product category (recorded video media) that was thoroughly legitimate and enjoyed essentially universal adoption. Unfortunately, it suffered several other problems. There was a strong network externality issue in that Blu-ray was engaged in a format war with HDDVD, and consumers understood that the losing format would lack content in the future. Blu-ray is only useful for owners of high-definition televisions (HDTVs), and only about one-third of American households owned HDTVs at the time of Blu-ray's release. Finally, the costs were high, with early players costing about $\$ 500$ and early discs being about twice as expensive as DVDs. Thus adopting a new innovation in this category would have required a person to own a relatively rare complementary technology, be interested in a relatively small improvement in quality and no improvement in convenience compared to DVDs, spend an appreciable amount of money, and take a substantial risk that a format war would render this investment obsolete. Thus it is not surprising that Americans were slow to take up the new format, even though basically all of them already accepted the basic product category of recorded entertainment on an optical disc.

Perhaps the most important scope condition for legitimacy to create exogenous diffusion is that there must be universal awareness. In the absence of an exogenous force (such as a marketing campaign) creating awareness of the innovation, only processes like word of mouth can create awareness, and so adoption would necessarily follow an endogenous pattern even if every potential adopter found the innovation to be so legitimate that the adopter adopted it immediately on being made aware of the innovation. 
The only claim is that for awareness and adoption of an innovation to be closely coupled, the innovation must derive legitimacy from categorical conformity. Numerous scope conditions outlined earlier show contingencies where an innovation from a well-established category could still fail to diffuse exogenously. Therefore such categorical conformity is a necessary, but not sufficient, condition for an innovation to diffuse exogenously.

Proposition 1: Only innovations that are nested within legitimate categories may have an exogenous diffusion pattern.

\section{Innovations from Novel Categories Will Spread Endogenously}

Although innovations can diffuse rapidly when they are nested within already established categories, in other cases, innovations are truly novel and represent the first member of a category to which a population is exposed. In such cases, the category has yet to achieve legitimacy with the population. As such, the innovation is not able to borrow the legitimacy of an incumbent category but must make the much more ambitious case for both its own worth and that of the category to which it belongs. These innovations are coterminous with the categories they inhabit, and so many "diffusion of innovation" studies are studying not only the diffusion of an innovation but the diffusion of a category.

For instance, the seminal hybrid corn study was studying not only the diffusion of a particular variety of maize but coterminously the practice of purchasing seed corn rather than reserving a part of the previous year's harvest (Rogers 2003; Ryan and Gross 1943). Although hybrid seeds grow into high-quality plants, they do not breed true, so a farmer must purchase commercially produced seed every planting season. This new business model offered higher crop yields but had the downside of exposing farmers to more debt. The result was that the coterminous diffusion of the category of hybrid seed and the innovation of hybrid maize was slow and involved great attention to peer behavior. The timing of adoption was consistent with an endogenous process, and in retrospective interviews, most farmers reported that they made the final decision to try the new seed only after seeing it work for neighbors. Likewise, much of the diffusion of innovation literature involves public health research in which women are encouraged to use family planning (Freedman and Takeshita 1969; Placek 1974; Rogers 2003). This may involve not just diffusing technical innovations like the pill or intrauterine devices (IUDs) but the much more arduous coterminous diffusion of "family planning," a new conception of gender relations and fertility in which women (rather than their husbands or fathers) are the locus of reproductive agency and children are not a blessing but a burden. The diffusion of IUDs among third world women in the 1960s is qualitatively different than the diffusion of the NuvaRing among American women in the last decade, because to the latter, the generic concept of scientific birth control is thoroughly familiar, even taken for granted.

This issue is much discussed in the diffusion of innovation literature, where it is mostly known not as categorical legitimacy but as "compatibility," which is "the degree to which an innovation is perceived as consistent with the existing values, past experiences, and needs of potential adopters" (Rogers 2003:240). A review of compatibility studies (mostly qualitative studies of failed public health and development campaigns) leads Rogers to "Generalization 6-2: The compatibility of an innovation, as perceived by members of a social system, is positively related to its rate of adoption" (p. 249). Rogers does not decompose "rate" into a constant and increasing component, but in all of his examples, he implies that compatibility will make the target audience more receptive to the entreaties of "change agents" such as salesmen or public health workers. Because such change agents are exogenous to the system, their efforts will not be an increasing function of local adoptions (Bass 1969). Thus we can extrapolate that innovations that are compatible with incumbent categories may diffuse with a constant hazard. In contrast, when innovations lack categorical legitimacy, they can only be legitimated by direct observations of peer behavior.

Proposition 2: Innovations that deviate from extant categories will either diffuse via increasing hazards or not at all.

Of course, the stock of categories itself is not static but can derive from experience. As the field gains successful experience with novel in- 
novations, their common properties become the basis for a newly familiar category, and future innovations along these lines benefit from legitimacy. As a category becomes more popular, it becomes more familiar and cognitively accessible such that future innovations along similar lines benefit by analogy with the extant innovation ${ }^{11}$ For instance, a few decades after hybrid corn seed conquered the corn belt, hybrid sorghum seed was introduced to Kansas. On strictly technical grounds, farmers in arid southwest Kansas would have benefited tremendously from adopting the new seed, but they did so slowly because they lacked experience with the concept of purchasing hybrid seed, and thus, to them, hybrid sorghum lacked legitimacy. In contrast, the seed was not especially useful in temperate northeast Kansas, but farmers there had experience with the analogous hybrid corn seed, and so in the first season, they planted 27 percent of their sorghum acreage with the new seed, and would have planted more of it, but they exhausted the seed company's inventory (Brandner and Strauss 1959).

Although this article has focused on categorical legitimacy, other sources of legitimacy that can broadly be referred to as institutionalization can provide legitimacy. For instance, legitimacy can also be promoted by the theorization of elites or the activism of social movements who articulate abstract rubrics for evaluating behavior, and these theoretical-political actions may be only loosely coupled to density (Green 2004; Rao 2009; Strang and Meyer 1993; Swidler 1986). These processes are often loosely coupled to but partially autonomous from categorical density. Institutionalization can be conceived of as practices not only spreading but taking root by developing a legitimating rhetoric and being integrated into social structure, including law and physical infrastructure (Baum and Powell 1995; Colyvas and Jonsson 2010; Green 2004). So whereas affirmative action began as a response to state demands that often consisted of just filing reports

\footnotetext{
${ }^{11}$ In addition to cognitive benefits, new innovations may benefit from compatibility with tangible infrastructure developed for earlier innovations in a category. For instance, if we think of e-books as a category and particular electronic book titles as innovations, e-books that are released later will benefit not only from the legitimacy the category has achieved with readers but also from the more practical benefit that there is now a large base of readers who own e-readers.
} developed an elaborate "diversity management' ideology advocated by an array of consultants and internal stakeholders within firms who promoted the perpetuation of affirmative action long after demands from the state abated (Dobbin and Sutton 1998; Kelly and Dobbin 1998). These dynamics are the mechanisms through which institutionalization occurs and are more powerful as the related innovations become more prevalent. Hence the relationship can be roughly approximated as density dependence (Hannan and Carroll 1992; Hsu and Hannan 2005) ${ }^{12}$ Firms in nascent industries suffer from a lack of legitimacy for their product category such that capital is hesitant to invest in the field and potential customers do not understand why the product is desirable, a pattern understood not only by the scholarly literature but also by the business press, which has noted that the paradox of innovative product launches is that to be successful, new product categories require both cognitive accessibility and ancillary services, but these conditions tend to exist only for mature product categories (Moore 1999). Regardless of mechanism, the more popular innovations within a category are, the more legitimate and cognitively accessible the category becomes. For instance, within broad categories of policy, earlier initiatives seem to legitimate subsequent initiatives such that the category as a whole, rather than just specific initiatives, seems to tip at a certain point 13

Proposition 3: Successful past experience with innovations from a heretofore novel category can institutionalize the category.

Earlier I reviewed the literature on diffusion of innovations and the nesting of innovations within categories and the related issues of institutionalism and "compatibility" with local culture. From this I derived three theoretical propositions. First, only innovations that are sufficiently legitimated

\footnotetext{
${ }^{12}$ Note that in organizational ecology, "density" is simply frequency rather than a ratio of frequency to some broader set. This article follows that literature in using density to mean a count, as distinct from the related concept of saturation, meaning the count as a fraction of the total population or ratio to carrying capacity.

${ }^{13}$ Studies of hate crime legislation across American states and neoliberal reforms across countries show that specific policies within these policy categories all tend to tip at the same time, around 1986 and 1993, respectively (Grattet, Jenness, and Curry 1998; Henisz et al. 2005).
} 
by conformity to categories can diffuse via "exogenous" patterns. Second, less legitimate innovations will diffuse endogenously or not at all. Third, successful innovations can institutionalize their product categories. In the next section, I formalize these propositions in a simulation.

\section{Simulation}

Simulations are useful for showing micro-macro emergence from parsimonious principles (Cederman 2005; Sawyer 2003). In this case, I show how coordination without communication can emerge from categorical legitimacy. Though the literature reviewed previously has tackled the issue of how legitimacy can affect diffusion, it has done so with the implicit or explicit assumption that the role of legitimacy is to catalyze more rapid endogenous diffusion, without understanding that it can also qualitatively change the nature of diffusion ${ }^{14}$ As shown in the following simulation, this assumption is only valid for relatively small legitimation effects. For more substantial legitimation, proximately exogenous diffusion patterns emerge from the threshold model of diffusion.

Threshold models treat each agent as having a threshold for adoption drawn from a distribution. When the innovation's popularity (with network alters and/or the field as a whole) exceeds the agent's threshold, the agent adopts (Abrahamson and Rosenkopf 1997; DiMaggio and Garip 2011; Granovetter 1978). The agent in this model can be seen as analogous to a nerve cell, which fires when incoming synapses meet the cell's particular threshold. Likewise, thresholds can be thought of as analogous to reservation prices in price theory, except adoption is not triggered by low price but rather by high popularity. The model is flexible enough that we can imagine that intrinsically appealing innovations (e.g., facially plausible ideas) may require less peer influence to be adopted than intrinsically unappealing innovations (e.g., facially bizarre ideas) (Centola, Willer, and Macy 2005). For instance, state legislatures may pass laws immediately when they are simple and salient to voters (such as "three strikes" for repeat criminal offenders) but wait to see how other states handle the proposal when

\footnotetext{
${ }^{14} \mathrm{~A}$ few recent publications in the political science "state policy diffusion" literature are a welcome exception (Boushey 2010; Nicholson-Crotty 2009).
}

the law is less obviously a political winner by virtue of its complexity and obscurity (such as "individual development account" tax-sheltered savings accounts for poor people) (Boushey 2010; Nicholson-Crotty 2009). In the following simulation, I model agents' thresholds as being sensitive to popularity of both the innovation itself and the category to which the innovation belongs. When the categorical density is high, the adoption curve at the innovation level becomes exogenous.

Like most simulations, this model is somewhat minimalist. Macy (2009) caution against nuanced "kitchen sink" models, as "analysis of very simple and abstract models can reveal new theoretical insights that have broad applicability, beyond the stylized models that produced them" (p. 264). Thus I will not attempt to specify how innovation diffusion might be channeled through network structure or articulate the various mechanisms through which categorical density creates legitimacy. Rather, I postulate these effects at a fairly abstract level and look to see what implications emerge.

The Stata code for the simulation is given in the supplement to this article and is referred to here by line number ${ }^{15}$ Start by assuming a population of agents with latent adoption thresholds drawn from a standard normal (lines 15-16). Let the agents assess an innovation that a small seed group has already adopted (lines 17-18). From here, we allow many time periods over which other agents beyond this seed group may adopt the innovation (line 23). An agent adopts an innovation in a particular time period if a random variable centered on the agent's latent adoption threshold is less than the (minimal) intrinsic appeal of the innovation plus the innovation-level and categorical-level endogenous effects (line 26). The simulation runs over many innovations within a category (line 20). The first innovation in the category has zero predecessors and so cannot benefit from categorical density, but each subsequent innovation benefits from the accumulation of precedent at the category level (lines 20 and 26).

That is, we allow the consecutive diffusion of a series of innovations within a category, and for

\footnotetext{
${ }^{15}$ I chose to write the simulation in Stata as it is a fairly intuitive language that is familiar to many sociologists. Lines not referred to and explained in the narrative are mostly housekeeping commands.
} 
each innovation within the category, we assume (in line 26) that agents are sensitive to both how popular the innovation is at a particular time and the popularity of the category to which the innovation belongs. Specifically, we assume an endogenous effect arbitrarily set such that every 20 percent of the population that has adopted increases the appeal of adoption sufficiently to meet the thresholds of another 1 standard deviation of agents ${ }^{16}$ Similarly, we can assume that agents are sensitive not only to how many peers have adopted the particular innovation but also to other innovations in the same category. We can arbitrarily set this sensitivity to categorical density such that every 20 extant innovations in a category make the new innovation 1 standard deviation more appealing 17

The results of the simulation are given as both a surface plot and a line plot in Figure 2 . In both plots, the horizontal is time because the innovation's launch and height are the innovation's saturation at time. The density of the category of which the innovation is a member is shown as depth in the surface plot and (for selected densities) as separate lines in the line graph. The first innovation within a category (frontmost in the surface graph or dots in the line graph) is s-shaped, but shallow, and only tips around the 13 th iteration. This indicates an endogenous growth process, albeit a slow one. As the category accrues density, the diffusion of each innovation is more rapid, but by the 20th category, it still follows a distinct s-curve. However, once categorical density reaches a critical mass in this simulation, about 30 or 40 extant innovations in the category, the curve for each new innovation changes qualitatively from an sshaped curve to a concave curve, indicating a diffusion process that is indifferent to proximate peer behavior and is usually interpreted as "exogenous." By the 60th innovation (rear of the

\footnotetext{
${ }^{16}$ Setting the endogenous effect higher provides similar results, but setting it lower implies that diffusion is always essentially exogenous. Similar results obtain if the simulation uses an additive instantaneous error term instead of centering an instantaneous random variable on the agent's latent tendency. Curious readers are invited to experiment with applying different parameters to the simulation program.

${ }^{17}$ I treat categorical density as the count of extant innovations for the sake of simplicity in this simulation. Substantially similar results obtain if categorical density is defined as the sum of innovation saturations.
}

surface graph or solid line in the line graph), the graph is completely concave.

Note that all of the numbers in the simulation are arbitrary and meaningful only relative to one another, but not in any absolute sense. For similar reasons, agent thresholds and innovation appeal do not have natural zeros but are expressed on the scale of a standard normal. Especially note that at what categorical density the innovation-level dynamic switches from endogenous to exogenous is a function of how sensitive agents are to categorical density, and this parameter is assumed by the simulation. The point of the simulation is not to pinpoint exactly what the critical mass of categorical density is but rather to show that if we assume agents to be sensitive to categorical density, then at some point, this implies a qualitative change for how innovations within that category diffuse. Once this occurs, we can meaningfully say that the category is institutionalized and innovations embedded within the category are ipso facto legitimate.

\section{Implications of the Simulation's Assumptions}

The preceding simulation deliberately uses parsimonious and clean assumptions because this allows for more tractable theory building than complicated and nuanced assumptions (Kanazawa 1998; Macy 2009; Tilly 2004). Nonetheless, social reality is messy, and so having accomplished the theory-building synthesis, it is worthwhile to discuss how sensitive it is to these assumptions and what the implications might be of changing them. Subsequently, I discuss implications of the following assumptions: the standard issues of the innovation-level Bass (1969) model, that categorical density has a direct and linear legitimation effect, that innovations fall neatly into discrete categories, and that categorical legitimacy effects are homogeneous across all agents.

Adoption is irreversible and not meaningfully spatial. This article adopts several assumptions at the innovation level from the Bass (1969) model, all of which are most relevant to the endogenous aspect of diffusion. The Bass model assumes that an agent's adoption of an innovation is discrete, irreversible, and perpetually contagious. These assumptions are realistic for many innovations over the short to medium term, but in other cases, 

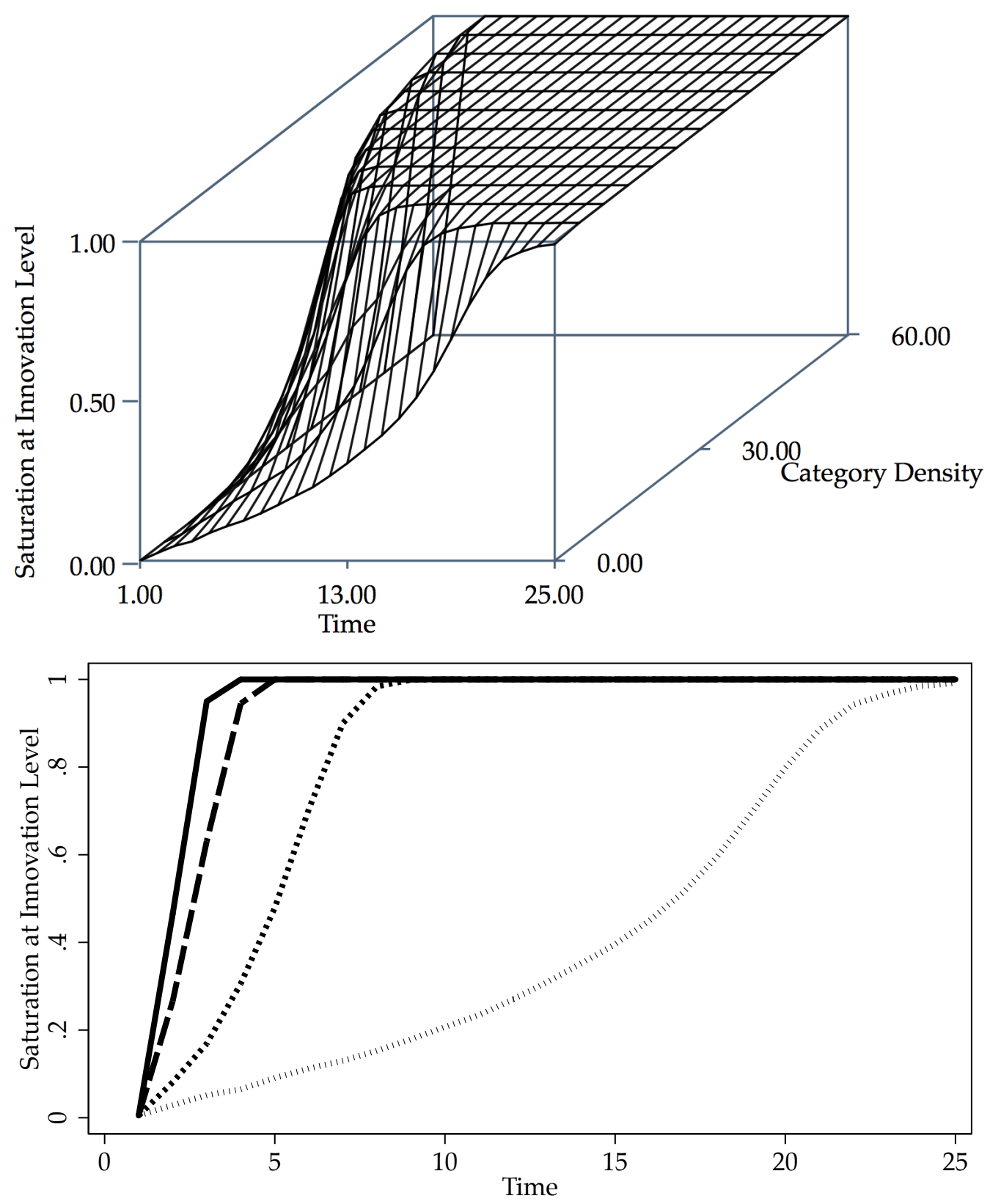

\begin{tabular}{|ccc|}
\hline \multicolumn{3}{|c|}{ Category Density } \\
$1 \ldots \ldots \ldots \ldots \ldots$ \\
Density $==0$ & $\cdots \cdots \cdots \cdots$ & Density $==20$ \\
- Density $==40$ & Density $==60$ \\
\hline
\end{tabular}

Figure 2: Simulated innovation diffusion by category density. 
a more elaborate model, such as the susceptibleinfectious-recovered (SIR) model in epidemiology, is appropriate.

Another simplifying assumption is the idea that endogenous diffusion occurs at the field level rather than through physical space, across a social gradient, or through network structure. This is a realistic assumption if we assume that agents are less attentive to local adoptions than to fieldlevel summaries of behavior (e.g., best-seller lists or retail inventories that prefer best sellers) (Anderson 2006; Salganik et al. 2006; Sorensen 2007). Alternately, even if diffusion does occur through network structure, the process is closely approximated by a nonspatial model if the social network has a low to moderate degree of segregation (DiMaggio and Garip 2011; Turchin 2003). So, for the most part, the simulation should be robust to the simplifying decision to specify generalized endogenous effects rather than contagion through an adjacency matrix.

However, there is one important way in which a network structure might affect the simulation of categorical density effects. Intrinsically unappealing innovations can only spread when networks are highly clustered and have few random graph elements, whereas intrinsically appealing innovations spread much more rapidly with the addition of random graph elements (Centola 2009; Centola and Macy 2007; Centola et al. 2005; Hedström, Sandell, and Stern 2000). Because in the simulation, innovations with low categorical density have little appeal, this implies that early in the development of a category, innovations will spread most rapidly through highly clustered network structures. Hence we might expect insular cliques to be especially fecund in birthing novel innovations, but once categories mature, new innovations within these categories will come from more integrated parts of the social system. This stylized model of how position in network structure changes as a category matures can be seen in the example of how new music genres often begin with tight-knit circles of artists and/or subcultures of ethnic or sexual minorities, but once the genre matures, songs and artists within it get taken up by major record labels and other firms at the core of the culture industry (Lena and Peterson 2008).

Legitimacy is a direct function of categorical density. At the categorical level, the simulation assumes that density directly translates into legitimation. This is partly based on the assumption that increased categorical density makes the category more cognitively accessible to the agent, but also that it increases the structural aspects of institutionalization, which Baum and Powell (1995) call sociopolitical legitimacy. The relationship between categorical density and cognitive legitimacy is probably fairly tightly coupled, that with sociopolitical legitimacy less so. Especially to the extent that we think structure is more important than cognitive accessibility, we can relax this assumption of tight coupling and allow more room for the agency of stakeholders, activists, institutional entrepreneurs, gurus, theorists, and so on (Briscoe and Safford 2008; Colyvas and Jonsson 2010; Dobbin and Sutton 1998; Green 2004; Rao 2009; Strang and Meyer 1993). Some specifications of imperfect mediation would preserve the simulation's general implications but would make the shift from "endogenous" to "exogenous" innovation-level diffusion even more abrupt. For instance, the mediation mechanism suggested by Green (2004) could be operationalized in the simulation by modeling discourse as a random quadratic function of categorical density. Alternately, we can imagine more complex models, where legitimacy is only loosely coupled to density (Colyvas and Jonsson 2010). The most plausible reading of these models is to see legitimacy as occurring when things resonate with preexisting meanings and social structures. Even then, such resonance may not be self-evident but may require time to be worked out, and thus density would interact with these preexisting sources of meaning in such a way that density would be a necessary but not sufficient condition for legitimacy ${ }^{18}$ Thus elaborating the mechanism through which categorical density is related to diffusion may make the dynamic more complex and subtle, but so long as it is related to density, such a model relaxation will preserve the broad outline of the relationship that autonomous but

\footnotetext{
${ }^{18} \mathrm{My}$ reading would seem to be contradicted by Colyvas and Jonsson (2010), who describe the possibility of things that are "accepted but not prevalent." However, it is debatable whether this cell is meaningful. Their examples to fill this cell mostly consist of legitimate formal structures that are prevalent but suffer from loose coupling to practice. Thus the purported existence of things that are "accepted but not prevalent" confuses prevalence with efficacy.
} 
simultaneous action presupposes legitimacy and legitimacy is usually related to categorical density.

Categories are discrete and unambiguous. A more complex issue is the treatment of categories as clear and discrete. This article assumes that an innovation is clearly nested within a single category (which may or may not be legitimate) and that categories are nominally distinguished, lacking adjacency, hierarchy, or confusion vis-àvis other categories. In fact, many market objects and actors are simultaneously within several categories, which implies such issues as focused or unfocused identities and niche width (Hsu 2006; Hsu and Hannan 2005; Zuckerman 1999). Likewise, new product categories do not come ex nihilo but are usually understood as offshoots or hybrids of existing forms (Kennedy 2008). This implies that the issue here called simply categorical density is not just how dense the category is but how plausible is the innovation's claim to the category, with the issue compounded if the innovation straddles several categories. Furthermore, literature on the problem of unfocused identities suggests that combining categorical identities cannot be reduced to anything as simple as the average legitimacy of all the categories to which the innovation is attached (Hsu 2006; Zuckerman 1999). Exploring the implications of categories in the plural is beyond the scope of this article, but it is interesting to note that it implies that there is not necessarily a natural zero for categorical density because almost any new category will not be completely novel but can make some kind of claims on earlier categories. This implies that successful institutionalization rhetoric should emphasize continuity with extant categories early on and then a distinct identity as the category matures (Kennedy 2008).

Actors have homogenous exposure to categories. A related assumption is that categorical density has homogeneous effects throughout the field. This assumption is somewhat unrealistic if we assume that categorical density works through mechanisms at or close to the actor level and that actors have substantial variance in their exposure to extant members of the category. So, for instance, we could array individual consumers on a continuum from technophobes to gadget geeks based on their individual familiarity with the product category of consumer electronics. Once the category of consumer electronics matures, such a scenario is likely to result in something like the Bass mixed influence curve, with the gadget geeks adopting any new gadget, immediately followed by endogenous diffusion promoting the new gadget to broader populations for whom the category is not as legitimate. Alternately, we can imagine that heterogeneity in exposure to a category is highly clustered at the group level. For instance, early Christianity was a synthesis of Judaism and Hellenism, and the resonance the new religion had with these systems of thought was more legitimating for Jews and Greeks than for Latins (Stark 1996) ${ }^{19}$ In the extreme case, we can imagine isolated populations of agents, and so categorical density is effectively categorical density for that population. A relaxed version of this scenario would be to imagine a situation in which groups are especially attentive to their own group but also sensitive to trends within other groups, such as consumers who are aware that a product, though new to them, was a big hit in the neighboring country (Dekimpe, Parker, and Sarvary 2000). Either the isolated or cosmopolitan scenario is compatible with the model presented in this article, so long as categorical density is specified relative to the salient population.

Although the simulation does not explicitly integrate the assumptions discussed here, the assumptions provide the opportunity for further theoretical elaboration. As discussed, relaxing most of these assumptions would complicate the model without changing its essence: that legitimate innovations can diffuse by constant hazard functions, that illegitimate innovations will diffuse by increasing hazard functions, and that as density in a category rises, future members of the category shift from the illegitimate to the legitimate pattern. In the final section, I discuss some implications of these inferences for the broader literatures on diffusion and institutionalism.

\footnotetext{
${ }^{19}$ Not only did Christianity reach thoroughly Hellenized regions such as Asia Minor much earlier than Latin regions such as North Africa, but even in the city of Rome, the early church mostly served Greek-speaking minorities. The church did not begin to develop a Latin liturgy or literature until the papacy of Victor I (AD 189-199), and it was only in the late fourth century that the church in the West became characterized by such Latin speakers as Ambrose, Jerome, and Augustine (MacCulloch 2010).
} 


\section{Conclusion}

This article has argued that if an innovation is situated within a highly legitimate category, the innovation can diffuse rapidly without the s-curve characteristic of cascades and contagion. Although actors may often be influenced by one another's behavior, drawing information from peers may be superfluous if the innovation is sufficiently compelling by virtue of its membership in an institutionalized category. When actors internalize shared expectations, they can each apply these rules directly, which creates a proximately atomistic pattern of behavior that is nonetheless collective through the mechanism of the shared expectations. Hence sufficiently strong shared understandings can create coordination without communication.

Consider the example of a religious service. Most religions do not expect the congregation to sit passively like bored undergraduates in a lecture but rather to engage in an elaborate choreography of kneeling, standing, sitting, bowing, chanting, reciting creeds, making various hand gestures, and so on. Devout congregants will anticipate the rhythm of the service such that a congregation composed entirely of such devout worshipers will see the onset of a ritual behavior follow an exogenous pattern as each worshiper responds directly to cues in the service. In contrast, infrequent worshipers will not be so practiced, and so a congregation composed mostly of infrequent worshipers will see the contagious onset of behavior as they do not necessarily attach any significance to the rabbi opening the ark or the reader placing the Gospels on the lectern but do notice that more and more people in the front pews have started standing and probably ought to be imitated. That is, the infrequent worshipers are more attentive to each other's prayer behavior than are the frequent worshipers. Hence a naive view of "social action" would lead us to the conclusion that the devout congregation at the weekday Mass or the morning minyan is less social than the merely annual attendees at an Easter or Yom Kippur service - a bizarre inference when one considers that it is the weak religious attachment of the holiday worshipers that leads them to imitate each other, as they lack the strong socialization into religious observance necessary to follow the service directly.
That is, "exogenous" behavior is really social in that the participants have such a strong set of shared expectations that peer behavior can be anticipated rather than waited for and observed. This can be the case even for behavior that is, in a theoretical (but not predictive) sense, density dependent. Coordination games are situations in which it is important that the actors converge on a common behavior, for instance, if several manufacturers hope to benefit from network externalities by agreeing on an industrial standard. These issues are density dependent in the sense that the payoff is a function of density and may in fact be density dependent in the sense of endogenous diffusion. However, actors can solve a coordination game simultaneously if they have sufficiently strong shared expectations so as to anticipate each other's behavior even without communicating (Schelling 1960). Many diffusion problems can be conceived of as protracted coordination games that can be most rapidly resolved through shared expectations. For instance, most people would feel embarrassed to be the only one applauding a speech, but a person can still do so without waiting for others because the institutional structure of rhetoric lets the person converge on anticipated peer behavior (Heritage and Greatbatch 1986). Going from a scale of seconds to a scale of months, many innovations are most useful if they are adopted widely, and so format wars tend to be resolved endogenously unless and until a trade group certifies a standard (Augereau, Greenstein, and Rysman 2006; Van den Bulte and Stremersch 2004; Dranove and Gandal 2003). Unlike state regulations, a trade group's standards are voluntary, but firms still comply, as the standard allows them to anticipate one another's future behavior. Institutions can serve to promote coordination without communication by providing a cognitive context through which innovations diffuse (Strang and Meyer 1993). Understanding how innovations are nested within institutions and categories can provide a means of bridging cultural and structural approaches, making the former tractable and the latter realistic.

\section{The Apparent Dearth of Constant Hazards in the Literature}

Note that because few innovations are thoroughly idiosyncratic, this suggests that many innova- 
tions would diffuse via constant hazard functions, which in turn raises the question of why the literature pays so much less attention to these patterns than to various endogenous processes. First, it may actually be the case that constant hazard functions are rare. The model presented in this article assumes certain auxiliary scope conditions, most notably that awareness be immediately universal. Adoption can never outpace awareness, and so a constant hazard for adoption presupposes an exogenous force (such as a marketing campaign or a decree from the central state) creating awareness. Another scope condition is effectively unlimited reproducibility, a condition that can be failed by manufacturing constraints, proprietary contracting, or intellectual property rights. Manufacturing constraints seem to have been a limit to what would have otherwise been almost immediate adoption of hybrid sorghum in the temperate regions of Kansas (Brandner and Strauss 1959). Thus, even if this article's theoretical model is valid, its results could fail to generalize if such scope conditions as immediate universal awareness and immediate universal availability do not prevail. In other words, categorical density may be a necessary but not sufficient condition for rapid diffusion of an innovation. However, there are cases in which the scope conditions are essentially unproblematic, especially circumstances in which a powerful actor has ensured widespread awareness but imposes no limitations on adoption. The tetracycline case is a good example because Pfizer went to great lengths to ensure that all physicians were aware of tetracycline and sent large stocks of it to pharmacies that would honor any doctors' prescriptions (Coleman et al. 1966). Likewise, the spread of pop singles among radio stations meets these scope conditions because there is a standard mechanical royalty and record labels heavily market songs to stations (Rossman et al. 2008). We might expect similar fulfillment of the scope conditions in any field with an active trade press and either open architectures or standardized nonexclusive licensing.

Second, there may be a case selection problem. Denrell and Kovács (2008) show in simulation that the "success bias" implied by the inability to empirically analyze failed innovations creates systematic biases in our understanding of diffusion. Similarly, there is a theoretical issue of case selection in that most diffusion studies in sociology are less interested in the diffusion of a particular innovation than they are in the diffusion of categories or institutions, and they tend to use innovations as indicators of categories or institutions, which themselves are latent. That is to say that sociologists tend to select cases in which a new innovation and a new category are diffusing coterminously, and thus the category has no density from which the innovation can borrow legitimacy. Thus it is not surprising that hybrid maize, IUDs, and central bank independence all follow a roughly s-shaped diffusion curve, as each was deliberately chosen by its researchers as a leading innovation within the categories of, respectively, agricultural extension service technologies, scientific birth control, and neoliberal reforms (Polillo and Guillen 2005; Rogers 2003; Ryan and Gross 1943). If we imagine a counterfactual research tradition in which researchers purposely select cases that are firmly situated within established categories, we might expect to see more cases in which these innovations diffused via constant hazards. Compared to sociology, marketing is less interested in large social and cultural shifts and more interested in the spread of particular products, and thus one testable implication of this speculation is that a meta-analysis comparing diffusion models in sociology to those in marketing would show more constant hazard functions in our sister discipline.

Third, publication bias and emphases in theoretical framing may be suppressing or downplaying findings of constant hazards. Endogenous processes - whether locally through networks or generally by means of cascades or externalitiesare a distinctly and obviously social class of phenomena. As such, the idea that fads are emergent from micro-interactions is exciting to a discipline that constructs its self-identity in opposition to methodological individualism. Given such an orientation, imagine the researcher who discovers (or the peer reviewer who reads) that a particular innovation diffuses such that in every period, proportion $h$ of holdouts adopt, and $h$ is not a function of whether ego's peers have adopted. Given that the inevitable question "is it sociological" answers itself when asked of endogenous processes, such a finding of diffusion by constant hazard must not seem like a positive finding but a disappointing failure to find contagion. 
Probably the best example of this is the seminal tetracycline diffusion study (Coleman et al. 1966). To a first approximation, doctors had a constant hazard function for adopting the drug, with the raw number of adoptions per month starting high and declining as the risk set became saturated. However, the tetracycline study is famous for being one of the first attempts to rigorously synthesize social network data and diffusion data, and both the original authors and many secondary analyses have emphasized the comparatively minor extent to which endogenous processes (i.e., cohesive contagion, structural equivalence contagion, and generalized cascades) can be found in the data and largely bracket the more substantial exogenous effects of the drug company's marketing efforts and medical journal articles about clinical trials (Burt 1987; Friedkin 2010; Strang and Tuma 1993; Van den Bulte and Lilien 2001). The contagion findings in the data are real, but it is telling that in the original report and most secondary analyses, they are given more emphasis than the much larger baseline constant hazard. The general sense seems to be that a good finding is social and that findings that appear to show individuals acting autonomously are more suited for the desk drawer, or at best a footnote in an article that emphasizes appropriately social findings. Indeed, the standard definition of diffusion "excludes atomistic decision-making processes where actor choices are uninformed by the activities or choices of others" (Strang and Meyer 1993:488). Bracketing the issue of whether our data have an obligation to us to be "social," the argument of this article is that what appears to be autonomous or exogenous may in fact be radically social and hence provides a justification and a road map for bringing the social back in, even to seemingly autonomous behavior.

\section{References}

Abrahamson, Eric and Lori Rosenkopf. 1997. "Social Network Effects on the Extent of Innovation Diffusion: A Computer Simulation." Organization Science 8:289-309. http://dx.doi org/10.1287/orsc.8.3.289

Anderson, Chris. 2006. The Long Tail: Why the Future of Business is Selling Less of More. New York: Hyperion.
Augereau, Angelique, Shane Greenstein, and Marc Rysman. 2006. "Coordination versus Differentiation in a Standards War: $56 \mathrm{~K}$ Modems." RAND Journal of Economics 37:887-909. http://dx.doi.org/10.1111/j 1756-2171.2006.tb00062.x

Banerjee, Abhijit V. 1992. "A Simple Model of Herd Behavior." Quarterly Journal of Economics 107:797-817. http://dx.doi.org/10 $2307 / 2118364$

Bass, Frank M. 1969. "A New Product Growth for Model Consumer Durables." Management Science 15:215-27. http://dx.doi.org/ $10.1287 / \mathrm{mnsc} .15 .5 .215$

Baum, Joel A. C. and Walter W. Powell. 1995. "Cultivating an Institutional Ecology of Organizations: Comment on Hannan, Carroll, Dundon, and Torres." American Sociological Review 60:529-38.http://dx.doi.org/10 $2307 / 2096292$

Berger, Jonah and Gael LeMens. 2009. "How Adoption Speed Affects the Abandonment of Cultural Tastes." Proceedings of the National Academy of Sciences 106:8146-50 http://dx doi.org/10.1073/pnas.0812647106

Bikhchandani, Sushil, David Hirshleifer, and Ivo Welch. 1992. "A Theory of Fads, Fashion, Custom, and Cultural Change as Informational Cascades." Journal of Political Economy 100:992-1026. http://dx.doi.org/10.1086/ 261849

Boushey, Graeme. 2010. Policy Diffusion Dynamics in America. New York: Cambridge University Press. http://dx.doi.org/10.1017/ CB09780511778834

Brandner, Lowell and Murray A. Strauss. 1959. "Convergence Versus Profitability in the Diffusion of Hybrid Sorghum." Rural Sociology 24:381-83.

Briscoe, Forrest and Sean Safford. 2008. "The Nixon-in-China Effect: Activism, Imitation, and the Institutionalization of Contentious Practices." Administrative Science Quarterly 53:460-91. http://dx.doi.org/10 2189/asqu.53.3.460 
Burt, Ronald S. 1987. "Social Contagion and Innovation: Cohesion Versus Structural Equivalence." American Journal of Sociology 92:12871335. http://dx.doi.org/10.1086/228667

Cederman, Lars-Erik. 2005. "Computational Models of Social Forms: Advancing Generative Process Theory." American Journal of Sociology 110:864-93. http://dx.doi.org/10 $1086 / 426412$

Centola, Damon. 2009. "Failure in Complex Social Networks." The Journal of Mathematical Sociology 33:64-68. http://dx.doi.org/ 10.1080/00222500802536988

Centola, Damon and Michael Macy. 2007. "Complex Contagions and the Weakness of Long Ties." American Journal of Sociology 113:70234. http://dx.doi.org/10.1086/521848

Centola, Damon, Robb Willer, and Michael Macy. 2005. "The Emperor's Dilemma: A Computational Model of Self-Enforcing Norms." American Journal of Sociology 110:1009-40. http://dx.doi.org/10.1086/427321

Clayman, Steven E. 1993. "Booing: The Anatomy of a Disaffiliative Response." American Sociological Review 58:110-30. http://dx.doi org/10.2307/2096221

Cleves, Mario, William W. Gould, and Roberto G. Gutierrez. 2004. An Introduction to Survival Analysis Using Stata. Rev. ed. College Station, TX: Stata Press.

Coleman, James Samuel, Elihu Katz, and Herbert Menzel. 1966. Medical Innovation: A Diffusion Study. Indianapolis: Bobbs-Merrill Co.

Colyvas, Jeannette A. and Stefan Jonsson. 2010. "Ubiquity and Legitimacy: Disentangling Diffusion and Institutionalization." Sociological Theory 29:27-53. http://dx.doi.org/10.1111/ j.1467-9558.2010.01386.x

Crane, Riley and Dider Sornette. 2008. "Robust Dynamic Classes Revealed by Measuring the Response Function of a Social System." Proceedings of the National Academy of Science 105:15649-653. http://dx.doi.org/10 1073/pnas.0803685105

sociological science | www.sociologicalscience.com
David, Paul A. 1985. "Clio and the Economics of QWERTY." American Economic Review $75: 332-37$.

Dawkins, Richard. 1976. The Selfish Gene. New York: Oxford University Press.

Dekimpe, Marnik G., Philip M. Parker, and Miklos Sarvary. 2000. "Global Diffusion of Technological Innovations: A CoupledHazard Approach." Journal of Marketing Research 37:47-59. http://dx.doi.org/10 1509/jmkr.37.1.47.18722

Denrell, Jerker and Balázs Kovács. 2008. "Selective Sampling of Empirical Settings in Organizational Studies." Administrative Science Quarterly 53:109-44. http://dx.doi.org/10 2189/asqu.53.1.109

DiMaggio, Paul J. 1987. "Classification in Art." American Sociological Review 52:440-55. http: //dx.doi.org/10.2307/2095290

DiMaggio, Paul J. and Filiz Garip. 2011. "How Network Externalities Can Exacerbate Intergroup Inequality." American Journal of Sociology 116:1887-1933. http://dx.doi.org/10 $1086 / 659653$

Dobbin, Frank and Frank R. Sutton. 1998. "The Strength of a Weak State: The Rights Revolution and the Rise of Human Resources Management Divisions." American Journal of Sociology 104:441-76. http://dx.doi.org/10 $1086 / 210044$

Dranove, David and Neil Gandal. 2003. "The Dvdvs.-Divx Standard War: Empirical Evidence of Network Effects and Preannouncement Effects." Journal of Economics and Management Strategy 12:363-86. http://dx.doi.org/10.1162/ 105864003322309518

Elias, Norbert. 1978. What is Sociology? New York: Columbia University Press.

Espeland, Wendy Nelson and Mitchell L. Stevens. 1998. "Commensuration as a Social Process." Annual Review of Sociology 24:313-43. http://dx.doi.org/10.1146/ annurev.soc.24.1.313 
Freedman, Ronald and John Y. Takeshita. 1969 Family Planning in Taiwan: An Experiment in Social Change. Princeton, NJ: Princeton University Press.

Friedkin, Noah E. 2010. "A Multilevel Event History Model of Social Diffusion: Medical Innovation Revisited." Journal of Mathematical Sociology 34:146-55. http://dx.doi.org/10 1080/00222500903221589

Gladwell, Malcolm. 2000. The Tipping Point: How Little Things Can Make a Big Difference. London: Little, Brown.

Granovetter, Mark S. 1978. "Threshold Models of Collective Behavior." American Journal of Sociology 83:1420-43. http://dx.doi.org/ $10.1086 / 226707$

Grattet, Ryken, Valerie Jenness, and Theodore R. Curry. 1998. "The Homogenization and Differentiation of Hate Crime Law in the United States, 1978 to 1995: Innovation and Diffusion in the Criminalization of Bigotry." American Sociological Review 63:286-307. http: //dx.doi.org/10.2307/2657328

Green, Sandy Edward Jr. 2004. "A Rhetorical Theory of Diffusion." The Academy of Management Review 29:653-69. http://dx.doi.org/ 10.5465/AMR. 2004.14497653

Hannan, Michael T and Glenn Carroll. 1992. Dynamics of Organizational Populations: Density, Legitimation, and Competition. New York: Oxford University Press.

Hedström, Peter, Rickard Sandell, and Charlotta Stern. 2000. "Mesolevel Networks and the Diffusion of Social Movements: The Case of the Swedish Social Democratic Party." American Journal of Sociology 106:145-72. http: //dx.doi.org/10.1086/303109

Henisz, Witold J., Bennet A. Zelner, and Mauro F. Guillen. 2005. "The Worldwide Diffusion of Market-Oriented Infrastructure Reform, 1977-1999." American Sociological Review 70:871-97. http://dx.doi.org/ 10.1177/000312240507000601

Heritage, John and David Greatbatch. 1986. "Generating Applause: A Study of Rhetoric and Response at Party Political Conferences." American Journal of Sociology 92:110-57. http://dx.doi.org/10.1086/228465

Hsu, Greta. 2006. "Jacks of All Trades and Masters of None: Audiences' Reactions to Spanning Genres in Feature Film Production." Administrative Science Quarterly 51:420-50. http: //dx.doi.org/10.2189/asqu.51.3.420

Hsu, Greta and Michael T Hannan. 2005. "Identities, Genres, and Organizational Forms." Organization Science 16:474-90. http://dx.doi org/10.1287/orsc.1050.0151

Iyengar, Raghuram, Christophe Van den Bulte, and Thomas W. Valente. 2011. "Opinion Leadership and Social Contagion in New Product Diffusion." Marketing Science 30:195-212. http://dx.doi.org/10 $1287 / \mathrm{mksc} .1100 .0566$

Kanazawa, Satoshi. 1998. "In Defense of Unrealistic Assumptions." Sociological Theory 16:193-204. http://dx.doi.org/10 1111/0735-2751.00050

Karpik, Lucien. 2010. Valuing the Unique: The Economics of Singularities. Princeton, NJ: Princeton University Press.

Katz, Elihu and Paul Lazarsfeld. 1955. Personal Influence: The Part Played by People in the Flow of Mass Communications. Glencoe, Il: Free Press.

Kelly, Erin and Frank Dobbin. 1998. "How Affirmative Action Became Diversity Management: Employer Response to Antidiscrimination Law, 1961 to 1996." American Behavioral Scientist 41:960-84. http://dx.doi.org/10.1177/ 0002764298041007008

Kennedy, Mark Thomas. 2008. "Getting Counted: Markets, Media, and Reality." American Sociological Review 73:270-95. http://dx.doi org/10.1177/000312240807300205

Leibenstein, H. 1950. "Bandwagon, Snob, and Veblen Effects in the Theory of Consumers' Demand." Quarterly Journal of Economics 64:183-207. http://dx.doi.org/10 $2307 / 1882692$ 
Lena, Jennifer C. and Richard A. Peterson. 2008. "Classification as Culture: Types and Trajectories of Music Genres." American Sociological Review 73:697-718. http://dx.doi.org/ 10.1177/000312240807300501

MacCulloch, Diarmaid. 2010. Christianity: The First Three Thousand Years. New York: Viking.

Macy, Michael and Andreas Flache. 2009. "Social Dynamics from the Bottom Up: Agent-Based Models of Social Interaction." Pp. 245-268 in The Oxford Handbook of Analytical Sociology, edited by Peter Hedström and Peter Bearman. Oxford: Oxford University Press.

Mahajan, Vijay and Robert A Peterson. 1985. Models for Innovation Diffusion. Beverly Hills, CA: Sage.

Marsden, Peter V. and Joel Podolny. 1990. "Dynamic Analysis of Network Diffusion Processes." Pp.197-214 in Social Networks ThroughTime, edited by Jeroen Weesie and Henk Flap. Utrecht, Netherlands: ISOR.

Moore, Geoffrey A. 1999. Crossing the Chasm: Marketing and Selling High-Tech Products to Mainstream Customers. Rev. ed. New York: HarperBusiness.

Nicholson-Crotty, Sean. 2009. "The Politics of Diffusion: Public Policy in the American States." Journal of Politics 71:192-205. http: //dx.doi.org/10.1017/S0022381608090129

Pae, Jae and Donald Lehmann. 2003. "Multigeneration Innovation Diffusion: The Impact of Intergeneration Time." Journal of the Academy of Marketing Science 31:36-45. http: //dx.doi.org/10.1177/0092070302238601

Phillips, Damon J. and Ezra W. Zuckerman. 2001. "Middle-Status Conformity: Theoretical Restatement and Empirical Demonstration in Two Markets." American Journal of Sociology 107:379-429. http://dx.doi.org/10 $1086 / 324072$

Placek, Paul J. 1974. "Direct Mail and Information Diffusion: Family Planning." Public Opinion Quarterly 38:548-61. http://dx.doi org $/ 10.1086 / 268182$
Polillo, Simone and Mauro F. Guillen. 2005. "Globalization Pressures and the State: The Worldwide Spread of Central Bank Independence." American Journal of Sociology 110:1764-1802. http://dx.doi.org/10 $1086 / 428685$

Randles, F. 1983. "On the Diffusion of Computer Terminals in an Established Engineering Environment." Management Science 29:46576. http://dx.doi.org/10.1287/mnsc.29.4 465

Rao, Hayagreeva. 2009. Market Rebels: How Activists Make or Break Radical Innovations. Princeton, NJ: Princeton University Press.

Rogers, Everett M. 2003. Diffusion of Innovations. 5th ed. New York: Free Press.

Rogers, Everett M. and Nancy Seidel. 2002. "Diffusion of News of the Terrorist Attacks of September 11, 2001." Prometheus 20:209-19. http: //dx.doi.org/10.1080/0810902021014326

Ross, Alex. 2010. "Hold Your Applause: Inventing and Reinventing the Classical Concert." Lecture given at the Royal Philharmonic Society, Mrch 7, 2010, London. Retrieved February 27, 2014 http://www.royalphilharmonicsociety . org.uk/?page=index $\cdot$ html\&id=109

Rossman, Gabriel, Ming Ming Chiu, and Joeri M. Mol. 2008. "Modeling Diffusion of Multiple Innovations Via Multilevel Diffusion Curves: Payola in Pop Music Radio." Sociological Methodology 38:201-30. http://dx.doi.org/10.1111/ j.1467-9531.2008.00201.x

Ryan, Bryce and Neal C. Gross. 1943. "The Diffusion of Hybrid Seed Corn in Two Iowa Communities." Rural Sociology 8:15-24.

Salganik, Matthew J., Peter Sheridan Dodds, and Duncan J. Watts. 2006. "Experimental Study of Inequality and Unpredictability in an Artificial Cultural Market." Science 311:854-56.http: //dx.doi.org/10.1126/science.1121066

Salganik, Matthew J. and Duncan J. Watts. 2008. "Leading the Herd Astray: An Experimental Study of Self-fulfilling Prophecies in an Artificial Cultural Market." Social Psychology 
Quarterly 71:338-55. http://dx.doi.org/10 1177/019027250807100404

Sawyer, R. Keith. 2003. "Artificial Societies: Multiagent Systems and the Micro-Macro Link in Sociological Theory." Sociological Methods \&6 Research 31:325-63. http://dx.doi.org/10 1177/0049124102239079

Schelling, Thomas. 1960. The Strategy of Conflict. Cambridge, MA: Harvard University Press.

Sorensen, Alan T. 2007. "Bestseller Lists and Product Variety." The Journal of Industrial Economics 55:715-38. http://dx.doi.org/ 10.1111/j.1467-6451.2007.00327.x

Stark, Rodney. 1996. The Rise of Christianity: A Sociologist Reconsiders History. Princeton, NJ: Princeton University Press.

Strang, David and John W. Meyer. 1993. "Institutional Conditions for Diffusion." Theory and Society 22:487-511. http://dx.doi.org/ 10.1007/BF00993595

Strang, David and Sarah A. Soule. 1998. "Diffusion in Organizations and Social Movements: From Hybrid Corn to Poison Pills." Annual Review of Sociology 24:265-90. http://dx.doi org/10.1146/annurev.soc.24.1.265

Strang, David and Nancy Brandon Tuma. 1993. "Spatial and Temporal Heterogeneity in Diffusion." American Journal of Sociology 99:61439. http://dx.doi.org/10.1086/230318

Swidler, Ann. 1986. "Culture in Action: Symbols and Strategies." American Sociological Review 51:273-86. http://dx.doi.org/ $10.2307 / 2095521$

Tilly, Charles. 1983. "Speaking Your Mind Without Elections, Surveys, or Social Movements." Public Opinion Quarterly 47:461-78. http://dx.doi.org/10.1086/268805

Tilly, Charles. 2004. "Observations of Social Processes and Their Formal Representations." Sociological Theory 22:595-602. http://dx.doi org $/ 10.1111 / \mathrm{j} .0735-2751.2004 .00235$.x
Tolbert, Pamela S. and Lynne G. Zucker. 1983. "Institutional Sources of Change in the Formal Structure of Organizations: The Diffusion of Civil Service Reform, 1880-1935." Administrative Science Quarterly 28:22-39. http: //dx.doi.org/10.2307/2392383

Travers, Jeffrey and Stanley Milgram. 1969. "An Experimental Study of the Small World Problem." Sociometry 32:425-43. http://dx.doi org/10.2307/2786545

Turchin, Peter. 2003. Historical Dynamics: Why States Rise and Fall. Princeton, NJ: Princeton University Press.

Valente, Thomas W. 1993. "Diffusion of Innovations and Policy Decision-Making." Journal of Communication 43:30-45. http://dx.doi.org/10.1111/j.1460-2466. 1993.tb01247.x

Van den Bulte, Christophe and Yogesh V. Joshi. 2007. "New Product Diffusion with Influentials and Imitators." Marketing Science 26:40021.http://dx.doi.org/10.1287/mksc.1060 0224

Van den Bulte, Christophe and Gary L. Lilien. 2001. "Medical Innovation Revisited: Social Contagion versus Marketing Effort." American Journal of Sociology 106:1409-35. http://dx doi.org/10.1086/320819

Van den Bulte, Christophe and Gary L. Lilien. 2010. "Two-Stage Partial Observability Models of Innovation Adoption." Technical Report, Wharton School, University of Pennsylvania.

Van den Bulte, Christophe and Stefan Stremersch. 2004. "Social Contagion and Income Heterogeneity in New Product Diffusion: A MetaAnalytic Test." Marketing Science 23:53044. http://dx.doi.org/10.1287/mksc.1040 0054

Watts, Duncan J. and Peter Sheridan Dodds. 2007. "Influentials, Networks, and Public Opinion Formation." Journal of Consumer Research 34:441-58. http://dx.doi.org/10 $1086 / 518527$

Weber, Max. 1978. Economy and Society: An Outline of Interpretive Sociology. Berkeley, CA: University of California Press. 
Wejnert, Barbara. 2002. "Integrating Models of Diffusion of Innovations: A Conceptual Framework." Annual Review of Sociology 28:297-326. http://dx.doi.org/10 1146/annurev.soc.28.110601.141051

Zuckerman, Ezra W. 1999. "The Categorical Imperative: Securities Analysts and the Illegitimacy Discount." American Journal of Sociology 104:1398-1438. http://dx.doi.org/10 $1086 / 210178$

Acknowledgements: This research benefited from National Science Foundation award SES0724914 and a Sloan Foundation Industry Studies Fellowship. The author is grateful to Ming Ming Chiu, Paul DiMaggio, Frank Dobbin, Nicole Esparza, Michèle Lamont, "Jade" YuChieh Lo, Joeri Mol, Stefan Timmermans, Lynne Zucker, the Innovation and Creativity Workshop at UCLA's Anderson School, and the participants at the ASQ-HEC-OMT conference on coordination.

Gabriel Rossman: Department of Sociology, University of California, Los Angeles. E-mail: rossman@soc.ucla.edu. 